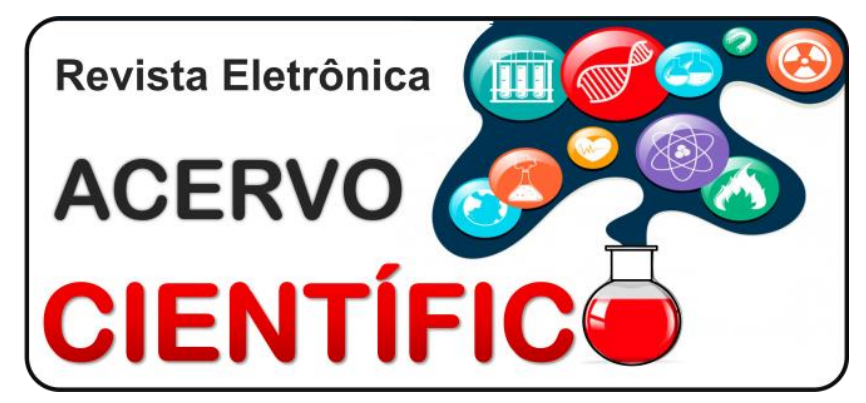

\section{REVISÃO BIBLIOGRÁFICA}

Recebido em: 10/2019

Aceito em: 11/2019

Publicado em: 1/2020

\title{
Docência superior na formação EAD no curso de enfermagem: Revisão bibliográfica
}

\author{
Higher teaching in distance education in nursing: Bibliographic review
}

\author{
Enseñanza superior en educación a distancia en enfermería: revisión bibliográfica
}

\begin{abstract}
Sônia Maria Rocha dos Santos ${ }^{1}$, Ronaldo Ferreira Pinheiro ${ }^{2 *}$, Mílvio da Silva Ribeiro ${ }^{3}$, Maria das Dores Martins de Oliveira ${ }^{4}$, Silvio Augusto de Almeida Hingel ${ }^{2}$.
\end{abstract}

\begin{abstract}
Resumo: Este artigo aborda sobre a docência superior na formação EAD e suas metodologias de ensino e aprendizagem no curso de graduação em enfermagem. O objetivo é descrever como ocorre a formação à distância e suas relações. O trabalho utiliza o método misto, em que a essência e o desafio é entender este processo frente a educação. Um processo sistemático e crítico que implica em uma conjugação de elementos qualitativo e quantitativos como possibilidade de ampliar as informações sobre o ensino em ambiente virtual. Diante destas necessidades despertou o interesse de pesquisar e apontar a importância desta educação por meio de levantamento de informações e revisão bibliográfica, procurando compreender a educação em suas qualidades, sem faltar o respeito de outras vozes, assim advir de fato uma ação comunicativa e entendedora de sua importância para Universalidade e a Integralidade equânime em consonância com a LDB 9394/96, BNCC e os decretos do MEC.
\end{abstract}

Palavras-chave: Docência; Metodologias; Instrução por computador.

\begin{abstract}
This article deals with higher education in distance education and its teaching and learning methodologies in undergraduate nursing. The objective is to describe how distance education occurs and its relationships. The work uses the mixed method, in which the essence and the challenge is to understand this process facing education. A systematic and critical process that implies a combination of qualitative and quantitative elements as a possibility to expand information about teaching in a virtual environment. Given these needs aroused the interest of researching and pointing out the importance of this education through information gathering and bibliographic review, seeking to understand education in its qualities, without disregarding the respect of other voices, thus in fact come a communicative and understanding action of its importance for Universality and Equalimity Integrality in line with LDB 9394/96, BNCC and MEC decrees.
\end{abstract}

Keywords: Teaching, Methodologies, Computer-assisted instruction.

1Universidade Anhanguera- Tucuruí - PA.

2Secretaria Estadual de Educação do Pará - SEDUC-PA, Tucuruí - Pará. *E-mail: ronaldofpinho@gmail.com

3Universidade Federal do Pará - UFPA / Faculdade Gamaliel (Fatefig), Tucuruí-PA.

${ }^{4}$ Universidade do Estado do Pará-UEPA, Tucuruí-Pará 
Resumen: Este artículo aborda la educación superior en educación a distancia y sus metodologías de enseñanza y aprendizaje en enfermería de pregrado. El objetivo es describir cómo ocurre la educación a distancia y sus relaciones. El trabajo utiliza el método mixto, en el que la esencia y el desafío es comprender este proceso que enfrenta la educación. Un proceso sistemático y crítico que implica una combinación de elementos cualitativos y cuantitativos como una posibilidad de expandir información sobre la enseñanza en un entorno virtual. Dadas estas necesidades, despertó el interés de investigar y señalar la importancia de esta educación a través de la recopilación de información y la revisión bibliográfica, buscando comprender la educación en sus cualidades, sin ignorar el respeto de otras voces, por lo que de hecho viene una acción comunicativa y comprensiva de su importancia para la universalidad y la integralidad ecuánime en línea con los decretos LDB 9394/96, BNCC y MEC.

Palabras clave: Enseñanza, Metodologías, Instrucción por computador.

\section{INTRODUÇÃO}

O mundo hodierno tomado pelas vertiginosas evoluções socioculturais geram incessantes mudanças nas organizações e no pensamento humano, uma delas é a implantação da Instrução por Computador, conhecida como Educação na Modalidade à Distância (educação EAD), que não visa ser uma forma oposta ou complementar do processo tradicional, sim uma educação do futuro com momentos virtuais outros presenciais e ela eleva o grau de flexibilidade no atendimento e nas necessidades do aluno que pretende adotar esta educação de excelência (MENEGHETTI FK, 2019).

A importância deste artigo se dá pelo expressivo crescimento dos cursos superiores na modalidade à distância. Precisamos estar atentos aos critérios da eficiência e da eficácia, baseado no planejamento estratégico sólido vindouro dos gestores, coordenadores e equipe multidisciplinar. Conforme dados do (INEP, 2019) a Educação EAD cresceu $133 \%$ nos últimos anos.

Ao situar o tipo de pesquisa utilizou-se o método mistos que fortalece o estudo online nos quais estão presente diversos processos e etapas que integram este processo, respeitou-se o alcance Exploratório, Descritivo, Correlacional Explicativo, com características de estatísticas simples, que além de proporcionar um sentido no entendimento dos fenômenos a que se faz referência, explica o propósito do trabalho e as classificações que pode variar de acordo com o objetivo pretendido onde o enfoque pode ser encaixado no método misto de (SAMPIERI RH, et al, 2013).

O presente trabalho objetiva convidar gestores, coordenadores, mediadores, acadêmicos e demais leitores para uma reflexão sobre as novas dimensões educacionais, destacando a educação a distância, e sua importância. Bem como, observar que muitas das falhas dessa modalidade de educação pode ser sanada conforme com a aplicação de metodologias ativas e os pressupostos andragógicos no processo de revisão de conceitos políticos e educacionais e aplicação da didática moderna para subsidiar os trabalhos da equipe gestora e dos professores mediadores de ensino superior no exercício de suas atividades docentes (ROCHA EF, 2019).

Este trabalho tem como objetivo trazer ao conhecimento um estudo sobre a docência superior na formação a distância no curso de enfermagem por meio de uma revisão bibliográfica sobre as principais abordagens em torno da temática.

\section{REVISÃO BIBLIOGRÁFICA}

\section{Formação EAD}

O curso a distância no Brasil, conforme registros, teriam seu início na década de 20, com a transmissão de curso pelas ondas de rádio, contudo, somente nas décadas de 40 e 50 que surgiram cursos formais com temas profissionalizantes tendo com referências o Instituto Monitor e o Instituto Universal Brasileiro. $\mathrm{Na}$ 
Década de 70 surgem as primeiras experiências com o fundamental completo e no final da década de 70 , em Brasília, surgem as primeiras experiências com cursos superiores (LUZURIAGA L,1983).

Até a década de 90 o grande modelo era o dos telecurso, com material impresso para o aluno, mas com o advento da internet a partir da década de 90 os materiais começaram a serrem disponibilizados online e a interações também passaram a se utilizarem desse canal e comunicação, culminando em 1996 com a criação da Secretaria de Educação a Distância (SEED) pelo Ministério de Educação. Em 2017 com a expedição do Decreto № 9.057, norma que atualizou a legislação sobre a regulamentação do ensino a distância no Brasil, houve crescimento de $133 \%$ dos polos EAD no país.

Com o avanço tecnológico da humanidade o ensino a distância evoluiu da mesma maneira que o mundo mudou, porém, o objetivo ainda é o mesmo: a disseminação do conhecimento para todo e qualquer indivíduo, rompendo com barreiras, principalmente as geográficas (DOHMEM G, 1967).

Conforme Assunção CM (2019) as Tecnologias Digitais de Comunicação e Informação (TDCls) potencializam a ampliação dos recursos disponíveis para a aprendizagem, favorecendo a aplicação de estratégias pedagógicas que atendem aos diversos estilos de aprendizagem e a incorporação de metodologias ativas que incentivam uma maior participação do aprendiz em seu processo educacional. Contudo, as limitações tecnológicas de regiões longínquas ainda limitam muito este processo. No curso de enfermagem as aulas práticas dependem de um laboratório local para que estas aulas ocorram in loco e não somente vitualmente.

Conforme podemos perceber, segundo dados do Inep (2019) no censo da educação superior, o ensino na modalidade de educação a distância apresentou um crescimento. $O$ número de vagas ofertadas pela Modalidade EAD superou em 2018 o número de vagas ofertadas em cursos presenciais. Segundo o censo foram ofertadas 7.170 .567 vagas remotas contra 6.358 .534 vagas presenciais. Em 2014 tínhamos 3.042.977 vagas para 7.170.567, um aumento significativo nos últimos 5 anos.

A escolha do tema se refere a uma questão de localidade, em meio a Amazônia, Cidade de Tucuruí-PA, o acesso ao ensino superior é muito limitado, na região era ofertado apenas uma curso de graduação na área de Saúde, na Modalidade presencial, contudo oferta de curso na Modalidade a distância abriu um leque imenso para o mercado. Atualmente com mais de 16 turmas formadas na região pela Universidade Anhanguera despertou a atenção a olhar para essa modalidade de ensino agregado ao fato da experiência de atuação profissional no referido curso (ROCHA EF, 2019).

Não podemos deixar de mencionar algumas das críticas feiras por Moran JM (1995) que apresenta algumas formas inadequadas, retruca o uso dos TDICs como transtorno, vídeo-tapa-buraco, vídeoenrolação, vídeo-deslumbramento da perfeição, ou somente vídeo, compromete o trabalho do professor, reforçando ainda, essa proposta de audiovisual considera uma simulação, do ensino aprendizado como dinâmica de analise, da leitura em conjunto, globalizante ou leitura funcional.

\section{Rompendo fronteiras}

A Formação EAD, modelo de Educação à Distância, vem sendo considerada uma forma alternativa ampliadora de horizontes no que diz respeito à capacitação e formação profissional, formação metodológica e científica com resignificância de proposta educativa enriquecedora da qual se utiliza as Tecnologias Digitais de Comunicação e Informação (TDCls) como ferramenta produtiva de conhecimento e estruturadora das tendências pedagógicas, da didática, do planejamento, do currículo e do processo avaliativo da formação à distância. Dohmem G (1967) conceitua a educação à distância enfatizando uma forma de estudo sistematicamente organizada, o estudo do material apresentado é acompanhado e supervisionado por uma equipe de professores, sendo isto possível graças às tecnologias de comunicação que ultrapassam longas distâncias, mas com uma produção de diálogo entre o usuário e essa tecnologia educativa.

A Educação EAD contribui significativamente com a criatividade da sociedade e no processo de inovação, um novo modelo educacional baseada na aprendizagem cooperativista e colaborativa, mediada 
pela internet, virtualidade que está proporcionando a transformação e/ou a adaptação das instituições tradicionais de ensino superior em uma modalidade de ensino que tem como aliada tecnologia de ponta com intuito de satisfazer as necessidades humanas, permitindo os acadêmicos irem além das tarefas propostas, em seu ritmo e estilo de aprendizagem (ASSUNÇÃO CM,2019).

Para um processo de formação em EAD ressaltamos que os conteúdos sejam "vivos" em um novo modelo que enfatiza o conteúdo indissociável da realidade agregando teoria, pratica e também experiências, professor como mediador dos conhecimentos e habilidades, um mediador que oportuniza os acadêmicos a serem capazes de criticar o modelo tradicional e também de transforma-lo por isso alunos transformador dos métodos relacionado, onde o professor busca relaciona-lo conhecimentos sistematizados à realidade do educando, um arcabouço da didática (LUZURIAGA L , 1983).

Para Luzuriaga L (1983) os quatro passos didáticos para se utilizar como educador podem ser citados como sendo: clareza; associação; sistematização e métodos. Clareza, é a preparação e a apresentação da matéria, associação, faz ligação entre as ideias antigas e novas. Sistematização, generaliza os conhecimentos. Método está ligado à fixação e a aplicação dos conhecimentos, Conforme Luzuriaga $L$ (1983) John Dewey reforça enfatizando a experiência, as atividades escolares devem centrar-se em situação de experiências, onde são ativadas as potencialidades naturais do aluno, ou seja, pra ele é inseparável, vida experiência e aprendizagem.

Para Libâneo JC (1989) a didática se baseia numa concepção de homem e sociedade, e, portanto, subordinam-se a propósitos sociais, políticos pedagógicos, os métodos que preconizo, mantém continuamente presente a vinculação entre educação e sociedade, percebe-se a vinculação entre educação e sociedade, ambos compartilham da mesma ideia com propósitos sociais e políticos.

Os primórdios da formação EAD num olhar de quem faz também é confundida com o Ensino Híbrido, um modelo de educação formal que tem por princípio unir dois modos de ensino, tradicional presencial e online. $\mathrm{Na}$ educação on-line geralmente o aluno estuda na comodidade de seu próprio espaço, se utiliza das ferramentas que podem desde guardar dados individuais do aluno aos dados de sua vida acadêmica, conteúdos estudados, dentre outros (DOHMEM G, 1967).

O ponto forte da formação EAD é a valorização das relações tutor/mediador, tutor/virtual, acadêmicos transformadores Coordenadores inovadores e significadores do processo de formação, todos conectados a um só objetivo, formação de qualidade, esforço bem sucedido para desenvolver um sistema de ensino a distância integrando aos meios digitais por meio de uma cultura cibernética dando origem a então Universidade de Educação a Distância (ROCHA EF, 2019).

A identidade do professor Universitário por vezes se perde nas funções que desempenhas em instituições e sociedade, as exigências caracterizadas pelo o exercício da profissão se tornam obsoleta dentro do próprio corpo docente, por falta de incentivo das Universidades e Faculdades não há diversidade de formações e capacitações oferecidas de acordo com a inovação tecnológica que estabelece as práticas didática do saber e dos diferenciais entres ás Universidades. Os avanços na educação raramente acompanham os avanços tecnológicos (MORAN JM, 1995).

Desta forma, podemos dizer que a necessidade de desenvolver ações de formação continuada para o provimento das deficiências dos profissionais que atuam na Educação Superior torna se urgente, especialmente porque muitos atuam na formação de docentes em Universidades como modelo tradicional (LIBÂNEO JC, 1989).

A educação a distância tem como foco principal complementar do processo presencial tradicional e não concorrer com ele, mas é sabido que ela é a educação do futuro, mesmo que postule momentos presenciais, semipresenciais ou totalmente virtual, ela respeita o elevado grau de flexibilidade nos atendimentos conforme às necessidades dos acadêmicos e das instituições de excelência em educação a distância. Tudo, está atrelado aos critérios de eficiência e eficácia, baseado em planejamento estratégico consolidado na didática moderna e nas tendências pedagógicas que vela pelos conteúdos vivos indissociável da realidade (MORAN JM, 1995). 
Sua solidez torna visível aos olhos de quem duvida da educação a distância, portanto não se pode ignorar a força da sociedade sobre os seus resultados, com a invasão das tecnologias na educação a distância que prima por gestores, coordenadores e tutores. Um espaço que está aberto para o diálogo comunicativo, essa comunicação virtual com tutores, acadêmicos e equipe multidisciplinares, por isso compete ao Gestor e Coordenador, delegar e corrigir eventuais falhas existente neste processo educativo, junto à esfera superior (LUCKESI CC, 2018).

\section{Formação da equipe EAD}

Para viver esta realidade a educação EAD visa a qualificação e preparação da equipe transdisciplinar, assim, inteirar os acadêmicos ingressantes neste processo a amabilidade que qualifica e prepara os novos profissionais para o futuro, daí a importância da capacitação e comunicação, peças essenciais para a sociedade discente no ato da filiação da equipe e no desenvolvimento desta visão educativa, pois se faz necessário mudar o foco do ensinar (ROCHA EF, 2019).

Então podemos dizer que esta realidade funciona a longo prazo e nos aproxima mais e mais da verdade educacional, na medida em que confrontamos teorias e práticas com os objetos pesquisados e dados coletados. A doutrina do falibilismo, em que, ás vezes nos leva a não entender a lógica do que está errado, mas com argumentos de que, uma vez que as leis da lógica são necessárias, então esta teoria passa a ser empregada no sentido mais amplo possível no sentido de fundamentar os paradigmas dos princípio filosófico da ética e da moral em educação, de que os seres humanos podem estarem certo ou errados sobre suas crenças filosóficas em pesquisas cientificas, expectativas ou compreensão do mundo (CARNEIRO MLF et al, 2005).

Daí se justifica a realização de seus fatos correto ou incertos, sendo impossível saber se atingimos a verdade a respeito de algo que pretendemos comprovar cientificamente, mais contamos com os conhecimento provisórios que são infalíveis, por exemplo, a visão de quem acredita na docência superior, uma educação que vem se modificando ao longo dos séculos, nos quais os instrumentos técnicos foram aperfeiçoados, assim é a EAD, uma educação virtual que transborda seus benéficos e suas qualidades(MORAN JM, 1995).

Hoffermann JML (1993) já avaliava a educação a distância com excentricidade, um novo modelo educacional, que configura suas dificuldades, mais ao avaliar a aprendizagem neste processo de ensino mediado tecnologicamente, discute-se a necessidade de revisão de conceitos e concepções sedimentados na qualidade e na busca de alternativas que conforme Rocha EF (2019) "se ajustem aos pressupostos teóricos de aprender e ensinar a distância".

Somos convidados por Hoffermann JML (1993) convida gestores, coordenadores, mediadores acadêmicos e leitores para uma reflexão que reitera (ROCHA EF, 2019) sobre as novas dimensões da avaliação na educação a distância, e ainda destaca (ROCHA EF 2019) "a importância das metodologias ativas e os pressupostos andragógicos no processo de revisão de conceitos políticos e educacionais", procedimentos que se aproxima das particularidades da educação a distância, transladando suas etapa avaliativas, como o universo da produção intelectual, onde tudo, está estruturado nos conhecimentos pedagógicos, nas tendências pedagógicas e na didática magna, mas que ainda carece de domínio das equipe educacional em didática moderna para subsidiar os trabalhos dos professores mediadores de ensino superior no exercício de suas atividades em docente.

Enfim, a série prática pedagógica e o web currículo, tem exatamente o objetivo de oferecer a esses mediadores materiais impressos e tecnológicos que sirvam como fontes de referência para 0 desenvolvimento de suas práticas na educação superior, ferramentas de suporte aos estágios dos futuros profissionais formados pela educação a distância e a desenvoltura do conhecimento multimedótico que há séculos vem sendo estudado nos mais diversos campos do conhecimento filosófico que, atualmente passou a ser um dos principais temas do conhecimento que é um conjunto de informações que o indivíduo adquire por meio da sua experiência, aprendizagem, crenças, valores e inteligências (CARNEIRO MLF E OLIVEIRA CC, 2005). 
Assim, a teoria da educação faz jus ao dito de Teruya, quando diz que as tecnologias são benéficas para a educação desde que saibamos utilizar, mas, para isso deve-se fazer uso das teorias e das tendências pedagógicas que visam novos meios promocionais de aprendizagem, através dos métodos relacionado o professor busca relacionar os conhecimentos sistematizados à realidade do aluno, objetivando dotar os indivíduos de comportamento flexíveis que lhe permitam ajustar-se às condições de uma sociedade em que as próprias necessidades de sobrevivências não estão garantidas (PEREIRA MFR et al. 2017).

Conforme as entrevistas e os depoimentos pudemos perceber que a instituição em análise apresenta inúmeras limitações quanto a aplicação de práticas metodológicas mais atuais, mesmo em um sistema tecnológico de educação a distância ainda temos professores que insistem em práticas tradicionais de educação. Quanto aos relatos da gestão se percebe que, mesmo já tendo sido identificadas as fraquezas e as ameaças, ainda são muitos os desafios diante de uma equipe que não se adequa ao processo, a falta de comunicação entre campus do interior e a sede, a demora na resposta das demandas solicitadas. A falta de comunicação tem corroído a instituição dia após dia e assim fica a mostra os grandes desafios da educação a distância que se encontra no lado humano de comprometimento do profissional e sobretudo na estruturação de um processo de gestão eficiente (DOHMEM G, 1967).

\section{CONSIDERAÇÕES FINAIS}

A educação à distância e os saberes construídos neste ambiente, saberes universitários, saberes experienciais, saberes disciplinares e saberes curriculares são as denominações dos saberes profissionais, são eles que preenche as lacunas deixada pela a formação institucional tradicional, outras foram utilizado como forma complementar em educação, em práticas educativas - como ensinar, o objetivo é oferecer determinados instrumentos que ajudem aos professores a complementar seu trabalho e sua didática conceituais no transdisciplinar. Enfim, se evidencia a comunicação verbal, escrita e virtual, acreditando que a comunicação verbal e não verbal entre todos, combinam com várias mídias, assim o projeto visa transparência diante dos conhecimentos, no caso da educação a distância, esta comunicação ocorre entre pessoas que já não estão todas no mesmo local e que necessitam, desta forma, de recursos tecnológicos que permitam a superação da distância, separados geograficamente, mas conectados através de recursos de comunicação, como as plataformas virtuais, correios eletrônicos, telefone, fax, Internet, videoconferência e o kahoot, concluímos as denominações das tendências pedagógicas que compartilha todos os conhecimentos nesta tese.

\section{REFERÊNCIAS}

1. ALMEIDA MEBA. Web Currículo Aprendizagem, Pesquisa e Conhecimento com o Uso de Tecnologias Digitais Aprendizagem e Mobilização: os dispositivos movem que criam novas formas de aprender, $1^{\text {a }}$ Ed. Editora Letra Capital - Rio de Janeiro 2014.

2. ASSUNÇÃO CM. Quais são os recursos de EAD que estão despontando no horizonte? In: Censo EAD.BR: relatório analítico da aprendizagem a distância no Brasil 2018 = Censo EAD.BR. 1ª ed. Curitiba: InterSaberes, 2019. página $9-12$.

3. CARNEIRO MLF, et al. Novas Tecnologias Na Educação, 3를 Ed. Rio de Janeiro: Editora FGV, Maio de 2005.

4. CARNEIRO MLF, OLIVEIRA CC. Referenciais éticos da educação a distância :uma experiência em cursos da UERGS. Novas Tecnologias CINTED-UFRGS na Educação. V. 3 № 1, maio, 2005.

5. CRESWELL JW. Metodologia De Pesquisa, tradução de Daisy Vaz de Moraes, editora penso, 5aㅡ edição, porto Alegre, 2010.

6. DEWEY J. Em Teoria Tradicional, referência a noções de movimento, transformação e mudança, São Paulo: Abril Cultural. Col. Os Pensadores. 2a. Ed. 1980.

7. DOHMEM G. Educação a Distância: abordagem histórica e contribuições. In: ALVES, o conceito de Dohmem em 1967.

8. HOFFMANN JML. Avaliação Mediadora Mito E Desafio: Uma Relação Dialógica na Construção do Conhecimento 9a edição Porto Alegre RS: Educação e Realidade, 1993. 
9. INEP. Censo da educação Superior 2018. Brasília: Mec, 2019

10. LIBÂNEO JC. O Papel Da Escola Segundo A Concepção de Libâneo -Democratização da escola pública: $8^{a}$. Ed. São Paulo: Loyola, 1989.

11. LUCKESI CC. Avaliação Da Aprendizagem Escolar: Questões Epistemológicas E Práticas, edição padronizada, Editora Cortez, São Paulo 2018, pag. 176.

12. LUZURIAGA L. História da educação e da Pedagogia. São Paulo: Cia Editora Nacional, 1983.

13. MENEGHETTI FK. Pensamento Crítico e Teoria das Organizações. Disponível in: <http://www.anpad.org.br/admin/pdf/enanpad2004-teo-2806.pdf> Acesso em 15.10.2019

14. MORAN JM. Internet no ensino. Comunicação \& Educação. V (14): janeiro/abril 1999, p. 17-26. NEGROPONTE, Nicholas. A vida digital. São Paulo: Companhia das Letras, 1995.

15. PEREIRA MFR, et al. Educação a distância (EaD): reflexões críticas e práticas. Uberlândia: Navegando Publicações, 2017.

16. ROCHA EF. Avaliação na EaD: estamos preparados para avaliar? mai. 2014.Disponível in: http://www.abed.org.br/site/pt/midiateca/textos_ead/1228/2014/05/avaliacao_na_ead_estamos_preparados_para_a valiar. Acesso em junho de 2019.

17. SAMPIERI RH, et al. Metodologia de pesquisa. 5 ed. Porto Alegre: Penso, 2013. 